\title{
Opportunities for Improved Potato Late Blight Management in the Republic of Ireland: Field Evaluation of the Modified Irish Rules Crop Disease Risk Prediction Model
}

\author{
Mladen Cucak, ${ }^{1,2, \dagger}$ Rafael de Andrade Moral, ${ }^{3}$ Rowan Fealy, ${ }^{2}$ Keith Lambkin, ${ }^{4}$ and Steven Kildea ${ }^{1, \dagger}$ \\ ${ }^{1}$ Teagasc Crops Research Centre, Oak Park, Carlow R93 XE12, Ireland \\ ${ }^{2}$ Department of Geography, Maynooth University, Maynooth W23 F2H6, Ireland \\ ${ }^{3}$ Department of Mathematics and Statistics, Maynooth University, Maynooth W23 F2H6, Ireland \\ ${ }^{4}$ The Irish Meteorological Service (Met Éireann), Glasnevin Hill, Dublin D09 Y921, Ireland \\ Accepted for publication 11 January 2021.
}

ABSTRACT

\begin{abstract}
Potato late blight remains the most significant disease threat of potato cultivation globally, often requiring expensive, time-consuming, and environmentally unfriendly approaches to disease management. The goal of this research was to evaluate whether an estimation of potato late blight risk based on environmental factors can be reliably used to adjust the standard potato late blight management practices and the role of cultivar resistance under growing conditions and contemporary Phytophthora infestans populations in the Republic of Ireland. The modified Irish Rules model made it possible to reduce fungicide usage by $58.7 \%$ on average, compared with current standard practices used by growers and without adversely compromising disease control and yield, with similar results achieved by the half-dose program. Host resistance levels were found to be correlated with a delay in the initiation of the epidemics, final foliar disease levels, and reduction of fungicide usage.
\end{abstract}

Disease levels on the highly resistant cultivars remained low, and a clear selection pattern toward the $P$. infestans genotypes EU_13_A2 and EU_6_A1 was observed. An increase in the frequency of strains belonging to genotypes EU_13_A2 and EU_6_A1 was also observed to occur in the latter part of the trial growing seasons. Because of the increasingly dynamic nature of the population structure, associated with the continued evolution of the $P$. infestans population and the arrival of EU_36_A2 in the Republic of Ireland, routine population monitoring is necessary to ensure that potato late blight control strategies remain effective.

Keywords: cultivar resistance, disease control, integrated pest management, pest management, Phytophthora infestans, plant disease forecasting, potato late blight, reproducibility
Potato late blight (PLB) caused by the oomycete Phytophthora infestans is one of the world's most devastating diseases of potato and tomato crops (Fry 2008). Historically, failure of the potato crop caused by PLB contributed to food shortages that resulted in dramatic changes in the demographics of Ireland in the mid-1800s (Austin Bourke 1964; Savary et al. 2017). Globally, the cost of control and associated yield losses are estimated to exceed $€ 1$ billion annually (Haverkort et al. 2008). In Ireland, the annual yield loss from the disease has been estimated at $8 \%$ (Copeland et al. 1993), with potential yield loss of $10.1 \mathrm{t} / \mathrm{ha}$ without fungicide protection (Dowley et al. 2008).

Cool and moist weather, typical in the northwestern part of Europe, provides optimum conditions for proliferation of PLB epidemics (Austin Bourke 1955; Cooke et al. 2011; Harrison 1995). The combination of shifts in the pathogen population since the 1980s, reliance on susceptible cultivars, and intensification of production makes this disease a high risk to potato production. Therefore, disease control is supported by prophylactic fungicide applications throughout the growing season, with treatment intervals

${ }^{\dagger}$ Corresponding authors: M. Cucak; mladencucak@gmail.com, and S. Kildea; Stephen.kildea@teagasc.ie

Funding: This work has been funded by the Irish Department of Agriculture, Food and the Marine under the EPIC project (RSF 14s879).

*The $e$-Xtra logo stands for "electronic extra" and indicates there are supplementary materials published online.

The author(s) declare no conflict of interest.

(c) (1) (5) $\ominus$ Copyright $(2021$ The Author(s). This is an open access article distributed under the CC BY-NC-ND 4.0 International license. as low as 5 days in high-pressure seasons (Cooke et al. 2011; Kirk et al. 2001). In addition to fungicide applications, management of the disease includes the use of healthy seed, appropriate removal of inoculum such as discarded tubers, frequent scouting of the crops, and the use of support tools to aid decisions related to the implementation of these measures.

$P$. infestans is a heterothallic species generally requiring the presence of both A1 and A2 mating types for sexual reproduction and recombination (Fry 2008; Goodwin et al. 1994). Before the late 1970s, global $P$. infestans populations were dominated by strains belonging to the A1 mating type, limiting the diversity that existed in populations. Since then reports of the A2 mating type have increased (Goodwin and Drenth 1997), facilitating the rise and spread of new lineages, some of which demonstrate higher fitness levels (Fry 2016). Currently, simple sequence repeats (SSRs) are the markers of choice for discrimination between $P$. infestans clonal lineages that share the same multilocus genotype (MLG) (a unique combination of alleles across two or more loci) (Fry 2016). Monitoring of $P$. infestans populations to capture their genotypic variation is routinely implemented by the USAblight group in the United States (www.usablight.org) and EuroBlight group (www. euroblight.net) in Europe and more recently in parts of Asia and Africa. Despite the low genetic diversity often found in Western European $P$. infestans populations, they regularly undergo frequent changes, such as an increase in the combined frequency of EU_13_A2 (13A2) and EU_6_A1 (6A1) MLG (Cooke et al. 2011) and, more recently, EU_36_A2 (36A2), EU_37_A2, and EU_41_A2 MLG (Cooke et al. 2019). Although the Irish population is dominated by EU_8_A1 (8A1), 13A2 and 6A1 have been reported in higher frequencies in recent years, although proportions vary from year to year (Cooke et al. 2014; Kildea et al. 
2010; Stellingwerf et al. 2018). The arrival and establishment of 13A2 and 6A1 MLGs in Ireland was somewhat delayed compared with the rest of the northwestern Europe, probably because of its location as an island on the western fringe of Europe. However, their arrival here has coincided with the foliar resistance ratings of several cultivars being downgraded from resistant to moderately resistant or even susceptible (Lees et al. 2012). These lineages also exhibit higher aggressiveness on susceptible cultivars that dominate Western European production systems (Mariette et al. 2016), including that of Ireland, where potato production is dominated by susceptible cultivars: Rooster (51.9\%), Kerrs' Pink (15.1\%), British Queen (8.6\%), and Golden Wonder (4.0\%) (Anonymous 2011), two of which, Rooster and British Queen, are included in this study.

Fry (1978) previously reported that combining cultivar resistance and regular applications of protective fungicides had an additive effect on controlling foliar PLB infections. For moderately resistant potato cultivars, reducing fungicide inputs for control of PLB has also been shown to be an effective control strategy (Bain et al. 2014; Fry 1975; Nærstad et al. 2007; Spits et al. 2007). More recently, Bain et al. (2014) demonstrated that even in the presence of aggressive $P$. infestans populations, reduced rates of protectant fungicides slowed the progress of epidemics, and cultivars with moderate levels of resistance performed similarly to resistant cultivars. However, $P$. infestans populations can adapt to locally dominant cultivars, irrespective of their resistance levels, and may render polygenic, partial resistance nondurable if not properly managed (Andrivon et al. 2007). Even among the highly clonal P. infestans population currently present in Ireland, Stellingwerf et al. (2018) reported that $13 \mathrm{~A} 2$ was found more often on cultivars with some level of resistance, indicating the potential for the selection of strains with higher virulence in local populations through cultivar deployment. Numerous examples from early PLB breeding efforts have shown that the deployment of major resistance genes (R-genes), which previously offered a high level of resistance, became rapidly ineffective through an increase in the frequency of the virulent isolates (Fry 2008). For example, in Scotland cultivar Pentland Dell contained the genes R1, R2, and R3 and was resistant to the common $P$. infestans race (Race 4), which led it to become the third most popular potato cultivar within 3 years of its introduction. This popularity led to selection of the resistance-breaking biotype in the local pathogen population and rapid degradation of cultivar resistance (Malcolmson 1969). Currently, attention is shifting toward stacking R-genes by conventional resistance breeding or genetic engineering techniques (Leesutthiphonchai et al. 2018).

A promising environmentally friendly strategy to prevent the resistance breakdown of potato cultivars under conditions of rapidly evolving pathogen population is to use disease risk prediction approaches, combined with pathogen monitoring, to guide more appropriate and tailored chemical protection and ensuring minimal chemical usage during periods of high disease pressure (Kessel et al. 2018). The use of decision support systems (DSSs) to help guide and reduce the use of fungicides for the control of PLB has shown promise around the world (Austin Bourke 1959; Fry et al. 1983; Grünwald et al. 2002; Hermansen and Amundsen 2003; Small et al. 2015) and in Ireland (Austin Bourke 1953; Dowley and Burke 2004). However, because of technical and perceptual constraints, the adoption of these systems in routine disease management has been perceived as slow (Gent et al. 2010; Raatjes et al. 2004; Shtienberg 2013). In the case of a high-risk disease, such as PLB, routine prophylactic applications of fungicide appear to be economically justified in the absence of an accurate disease risk model (Pethybridge et al. 2009).

Recently, Cucak et al. (2019) undertook an extensive evaluation of the PLB model used in Ireland, the Irish Rules (IR), with a view to integrating it into a DSS for growers. The IR (Austin Bourke 1953 ) is a semiempirical PLB risk prediction model developed in the 1950 s to accommodate the PLB pathosystem, management practices, and suitability of the operational meteorological network in Ireland. Despite changes in the PLB pathosystem, limited evaluation of the model (Dowley and Burke 2004), and questions about its performance (Dowley and Burke 2004; Hansen et al. 2017), the IR is still used in its original form to support the PLB warning service by issuing spray advice, operationally led by the national meteorological service, Met Éireann (Dowley and Burke 2004). A previous evaluation by Dowley and Burke (2004) reported that although a significant reduction in fungicide usage was achieved with the model, the disease control was not satisfactory. More recently, a theoretical comparison of the currently used PLB risk prediction models in Europe, implemented within the IPMBlight 2.0 project (Hansen et al. 2017), showed that the IR model produced the lowest risk accumulations (quantity of estimated risk per a period of time) of all models evaluated, because of its conservative set of parameters. Consequently, Cucak et al. (2019) recalibrated the model and the decision strategy. The following changes were recommended: reducing the thresholds for relative humidity and an initial period duration from $90 \%$ and $12 \mathrm{~h}$ to $88 \%$ and $10 \mathrm{~h}$, respectively; keeping the temperature threshold at $10^{\circ} \mathrm{C}$; and adopting a leaf wetness indicator that incorporates both precipitation $(0.1 \mathrm{~mm})$ and relative humidity $(90 \%)$. Based on the revised model, Cucak et al. (2019) demonstrated that although the disease outbreak can occur after three effective blight hours (EBH; a unit of risk as estimated by the IR model), the minimum accumulation can go up to $11 \mathrm{EBH}$. Although the reduction of the model variable thresholds inevitably results in an increase in risk estimation, the results of the simulation analysis showed that, theoretically, the reparameterized model still provides for reductions in fungicide usage while achieving good predictive ability.

Given the potential production risks associated with failing to control PLB under Irish growing conditions, a field evaluation of the revised model and decision strategy was subsequently implemented in order to further evaluate the previous theoretical analysis. Our aim was to show how subtle adjustments of the standard grower's practice, using a reliable, publicly available decision support tool, are possible under Irish conditions. Our specific goals were to assess the performance of fixed and environmentally guided adjustments of the standard grower's PLB fungicide program in terms of foliar disease control, the effect on yield, the role of varietal resistance, and possible implications for these changes in practice on the local $P$. infestans population. Importantly, we provided all of the code used in the methods and the analysis of this study as open source to facilitate and encourage further evaluation and development of integrated pest management strategies, according to the principles set in our previous study.

\section{MATERIALS AND METHODS}

Frequently used abbreviations are presented in Table 1.

Trial design and agricultural practices. Field trials were conducted at the Teagasc Crops Research Centre at Oak Park, Carlow, Ireland (latitude: $52.85^{\circ}$, longitude: $-6.91^{\circ}$ ) during the growing seasons 2016 to 2019. Fertilization and nonexperimental pesticide applications, preemergence herbicide, and insecticides were applied according to local potato growing practices (Supplementary Table $\mathrm{S} 1$ ). In each season the preceding crop was spring barley (Hordeum vulgare), with the potato crop representing the noncereal break crop in a 5-year rotation. The soil at the Oak Park site is described as fine loamy drift with limestones, which falls into a typical subgroup of luvisols (Environmental Protection Agency 2014). The planting dates were approximately 1 month later than the standard grower's practice (late March to early May) (Supplementary Table S1) to avoid plant senescence toward the end of the season, and PLB was allowed to develop naturally. Because of an extended dry period that lasted from mid-May to mid-July 2018, the trial was irrigated on two occasions (14 June and 28 June) to prevent abiotic impacts 
of drought. The irrigation had no impact on disease development because the first disease occurrence was not recorded until 20 August of that growing season. The entire trial was desiccated in late September, and harvesting took place in October of each growing season. Drills in each plot were mechanically lifted and tubers were hand-picked from the soil surface. Potatoes were stored in open storage for $\geq 2$ weeks to allow tuber blight symptoms to develop. Dates of the agronomic operations are presented in Supplementary Table S1.

The trial was designed as a split plot with two factors: a fungicide program randomized to the whole plots and potato cultivars to subplots, with four replications. The subplot consisted of 20 tubers of each cultivar per replicate. Factors are described below. The trials were planted into preformed 81-cm-wide ridges, with $31 \mathrm{~cm}$ of planting distance between tubers. Each main plot was made up of six drills $11.3 \mathrm{~m}$ long, with subplots consisting of two drills each with 10 plants. To facilitate harvesting, $1 \mathrm{~m}$ was left unplanted at the end of each subplot. In addition, the middle two drills of each plot were planted with PLB-susceptible potato cultivar King Edward to allow a uniform development of the disease. A 3-m divider strip was left between the replicates to facilitate fungicide application and avoid interplot interference. Spraying was carried out with a conventional sprayer mounted on a utility vehicle with an independent power source. The spray volume was 200 liters/ha, and the spray pressure was 3 bars to give a medium/fine spray quality with antidrift spray nozzle number 4110-20.

Cultivars. Six potato cultivars (Table 2) were included in the trials and were selected because they represent either those most widely cultivated in Ireland or those that lie at opposite ends of the resistance and susceptibility spectrum of cultivars currently available. The clone T821/11 from the Teagasc potato breeding program was also included to represent current breeding material with resistance. Certified seed tubers were acquired from commercial sources, with the exception of T5821/11, which was propagated as part of the Teagasc potato breeding program.

Disease control. We followed the approach outlined by Madden and Ellis (1988), that an appropriate validation of a warning system should include a comparison of a DSS-generated program with a standard spray program and a no-fungicide control. In this study, all infections were natural. The application of fungicides commenced when the plants were beginning to meet within the drills. Six PLB control programs based on 7-day intervals were used in the trials: 1 , untreated control; 2 to 3 , full and half-label dose of fungicide program considered a standard grower's practice (further referred to as the full and half dose), respectively; and 4 to 6, standard grower's fungicide program adjusted based on the highest disease risk prediction for the 7-day period after a fungicide application, determined as follows:

TABLE 1. List of frequently used abbreviations and their full forms

\begin{tabular}{ll}
\hline Abbreviation & \multicolumn{1}{c}{ Full form } \\
\hline GLMM & Generalized linear mixed model \\
IPM & Integrated pest management \\
PLB & Potato late blight \\
AUDPC & Area under the disease progress curve \\
rAUDPC & Relative area under the disease progress curve \\
BQ & British Queen \\
KE & King Edward \\
RO & Rooster \\
SE & Setanta \\
CL & Clone from Teagasc breeding program \\
SM & Sarpo Mira \\
IR & Irish Rules model \\
MIR & Modified Irish Rules model \\
IRp & Irish Rules program \\
MIRp & Modified Irish Rules program \\
BMp & Blight management program \\
EBH & Effective blight hours \\
\hline
\end{tabular}

- Irish Rules program (IRp): full dose applied if the IR model output reached the threshold of $12 \mathrm{EBH}$ as per Austin Bourke (1953); otherwise, treatment was not applied.

- Blight Management program (BMp; included in 2017 to 2019): adjusted dose applied based on a limited version of Blight Management including only model A (for susceptible cultivars) as per Nielsen et al. (2018) (Supplementary Table S2) without altering our fungicide program (curative treatments recommended by Blight Management were not implemented).

- Modified IR program (MIRp included in 2017 to 2019): adjusted dose applied based on risk predicted by the MIR model as per Cucak et al. (2019), with doses applied (five categories: no treatment, quarter, half, three quarters, and the full dose) reflective of respective risk accumulations of EBH: 0 to 3, 4 to 6, 7 to 9,10 to 12 , and $>12$.

The fungicide programs included in the study were typical of locally applied Irish programs including the following fungicides applied in rotation (the active substance, concentration, and the label dosage are indicated in brackets): Ranman (cyazofamid $400 \mathrm{~g} /$ liter, 0.5 liter/ha), Shirlan (fluazinam $500 \mathrm{~g} / \mathrm{liter}, 0.4$ liter/ha), Infinito (fluopicolide 625 g/liter + propamocarb $62.5 \mathrm{~g} /$ liter, 1.6 liter/ha), and Revus (mandipropamid $250 \mathrm{~g} /$ liter, 0.6 liter/ha). In all cases, the recommended label dosage was considered the full dosage. See Supplementary Table S3 for further details on dates of application and dosages applied for each treatment.

An automated service to run the risk prediction models was implemented in the R programming language ( $\mathrm{R}$ Core Team 2018). For each PLB control strategy, the risk was calculated based on observed and forecasted hourly weather data relevant for the trial location. The files with observed weather data contain hourly values for the following variables: mean air temperature $\left({ }^{\circ} \mathrm{C}\right)$ and relative humidity $(\%)$ at $2 \mathrm{~m}$ and total hourly precipitation $(\mathrm{mm})$ measured at the Oak Park synoptic weather station, operated by Met Éireann. All trials were within a radius of $500 \mathrm{~m}$ from the meteorological station. The weather forecast data were extracted from the nearest grid point of the high-resolution forecast atmospheric model, operationally run by the European Centre for Medium-Range Weather Forecasts. The high-resolution forecast grid resolution is approximately $9 \mathrm{~km}$. The weather forecast data consisted of three files with intervals from 0 to 90,120 , and $240 \mathrm{~h}$ lead time with the corresponding 1-, 3-, and 6-h temporal resolutions, respectively. Files were merged for the entire 240 -h period. Temperature and relative humidity were temporally scaled to hourly resolution by spline interpolation via the Forsythe, Malcolm, and Moler method (Forsythe et al. 1977), and the rain totals were divided by 3 for 3-hourly and 6 for 6-hourly files. Data files were obtained from Met Éireann daily at 09:30 UTC; the observed files are then concatenated with the 240 -h weather forecast, starting from the midnight of the current day. The automated service ingests the weather data and generates the dosage calculation for the respective fungicide application on the current day and graphic outputs of the model calculations for the next 7 days (Supplementary Fig. S1).

Disease and yield assessments. Disease severity, assessed as the proportion (\%) of diseased crop tissue in each subplot, was estimated visually in accordance with the Agricultural Development and Advisory Service of the United Kingdom PLB foliage assessment key (Anonymous 1976) every 3 to 7 days. The assessments were initiated after the disease was first observed in the trial site and continued until the untreated control plots were completely necrotic or plants were naturally senescing.

Each subplot was mechanically harvested, with tubers subsequently picked by hand. After harvesting, the tubers were stored at ambient temperature for 3 to 6 weeks. Tubers were then graded; all tubers between 45 and $85 \mathrm{~mm}$ were considered marketable yield. The weight of harvested tubers per plot $\left(\mathrm{m}^{2}\right)$ was rescaled to actual yield, expressed as tonnes per hectare, without adjustment for the effect of small plot size. 
Pathogen sampling and molecular characterization. Collection and isolation. We collected pathogens by sampling infected potato leaflets from each plot, with visible disease symptoms, at the end of the epidemic in 2016 and at different stages of the epidemic development during the growing seasons from 2017 to 2019 (see Supplementary Table S4 for sampling dates and Supplementary Table S5 for the number of isolates per cultivar and factor per year). The number of samplings varied per plot and growing season and was dictated by the stage of epidemics and its rate, as well as suitability of weather conditions for sampling. The number of lesions collected per plot was reciprocal to the disease progress, with a maximum number of four lesions per plot. However, in the case of a single lesion present in a plot, only a half of that lesion (and leaflet) was collected to avoid disturbing the progress of epidemics. Single $P$. infestans lesions were identified and pressed onto Whatmann FTA cards (GE Healthcare), with the exception of 2017, when live cultures were also isolated as follows: Cuttings of the sporulating lesions were placed on the bottom of Petri dishes, underneath a lifted pea agar media (160 $\mathrm{g}$ of peas per liter and $1.5 \% \mathrm{wt} / \mathrm{vol}$ agar) amended with rifampicin (37.5 mg/liter), ampicillin (10 mg/liter), and nystatin (37.5 mg/liter). Petri dishes were closed with Parafilm and incubated at $18^{\circ} \mathrm{C}$ in darkness. When clear aerial mycelial growth was visible, approximately 5 to 7 days after isolation, a piece of mycelium was transferred to a fresh pea agar medium with a sterile scalpel blade and incubated at $18^{\circ} \mathrm{C}$. Axenic isolates of $P$. infestans were transferred to pea agar for subsequent DNA extraction and transferred onto the rye agar slopes (Caten and Jinks 1968) for long-term maintenance at $4^{\circ} \mathrm{C}$.

DNA extraction. A single 2-mm disc was punched from the FTA cards and transferred into $1.5-\mathrm{ml}$ 96-well PCR plates. The disc was washed three times with $400 \mu \mathrm{l}$ of the FTA purification reagent (Whatman Inc., Piscataway, NJ) followed by two rinses with $400 \mu \mathrm{l}$ of Tris-EDTA buffer (10 mM Tris and $0.1 \mathrm{mM}$ EDTA). The disks were dried for $2 \mathrm{~h}$ in a laminar flow, after which they were kept at $4^{\circ} \mathrm{C}$. PCR amplification was implemented within 4 days.

For the $P$. infestans isolates, pieces of lyophilized mycelium were placed in a 2-ml polypropylene vial with glass beads and homogenized. The tissue was disrupted with a mixer mill (MM400 Retsch). DNA extracted with the MagMAX Plant DNA Kit (A32580, ThermoFisher, Waltham, MA) on a King-Fisher 96DW instrument (Thermo Scientific, Waltham, MA) and stored at $-20^{\circ} \mathrm{C}$. DNA concentration was measured with a NanoDrop 2000 Spectrophotometer (Thermo Scientific) and adjusted to $10 \mathrm{ng} / \mu \mathrm{l}$.

Microsatellite genotyping. The standardized set of 12 microsatellite markers (Pi02, Pi4B, G11, Pi04, Pi63, Pi70, D13, SSR2, SSR4, SSR6, SSR8, and SSR11) (Knapova et al. 2002; Lees et al. 2006; Li et al. 2010) was used to amplify the SSR regions of $P$. infestans isolates. Amplification of the SSR markers was carried out as previously described ( $\mathrm{Li}$ et al. 2013). PCRs were performed with Qiagen Type-it Microsatellite PCR kit (Qiagen, Hilden, Germany) in accordance with the manufacturer's instructions. Primers labeled with a fluorescent dye (G5 dye set: 6-FAM, NED, VIC; Applied
Biosystems, Bedford, MA) were used. Samples from 2016 were analyzed with an ABI 3130xl and those from 2017 to 2019 were analyzed with an ABI 3500XL capillary DNA sequencer according to the manufacturer's instructions (Applied Biosystems). SSR allele size was determined relative to GeneScan 500 LIZ standard, and scoring was undertaken in GeneMapper version 3.7 (Applied Biosystems). MLGs were assigned as per allele sizes from Stellingwerf et al. (2018).

Data analysis. The entire analysis was implemented in $\mathrm{R}(\mathrm{R}$ Core Team 2018). The research compendium, containing the entire data analysis, is archived at https://mladencucak.github.io/ PLBFieldTrial/index.html.

Disease control and yield analysis. The disease observations were used to calculate the area under the disease progress curve (AUDPC) (Campbell and Madden 1990), which was then normalized by dividing the AUDPC by the total area of the graph to calculate the relative area under the disease progress curve (rAUDPC) (Fry 1978) to enable comparison between treatments with different assessment periods. The rAUDPC was calculated with the $\mathrm{R}$ "agricolae" package (Mendiburu 2014). The values of the response variable, rAUDPC, are unitless proportions ranging from 0 to 1 , and beta generalized linear mixed models (GLMMs) with a logit link were fitted in the package "glmmTMB" (Brooks et al. 2017). GLMMs could be used for data analysis with greater heterogeneity of disease incidence than would be expected from the random pattern (Madden et al. 2002). Models were fitted to the first year, and remaining years separately, because of the lack of two levels of experimental factors (variety and fungicide program) in 2016. The effects of block and plot were included as a random variable in the linear model. The fixed-effect components were fungicide program, cultivar, and the interaction between fungicide program and cultivar for the first growing season (2016), and for the remaining seasons (2017 to 2019), the three-way interaction between program, cultivar, and year was also included. Under the same procedure, a linear mixed effect model was fitted to the yield data in the package "lme4" (Bates et al. 2015). The higher-order interactions of models fitted to disease and yield were significant between fungicide program and cultivar in 2016 (Wald $\chi^{2}[42, n=64]=60.1, P<$ 0.001 and Wald $\chi^{2}[16, n=64]=23.8, P=0.004$, for the foliage disease and yield, respectively) and between year, fungicide program, and cultivar in the remaining years (Wald $\chi^{2}[432, n=72]=$ $85.7, P=0.0014$ and Wald $\chi^{2}[432, n=72]=160.9, P<0.001$, for the foliage disease and yield, respectively), and hence all terms were kept in models for both disease and yield.

Goodness of fit of the models was evaluated for plots of residuals. In addition to plots of residuals, half-normal plots with simulation envelopes were used to assess the goodness of fit of the models fitted to the yield data, in the package "hnp" (Moral et al. 2017). ANOVA-like tables were calculated via Wald $\chi^{2}$ test statistics to test the effects of the fixed factors, via the ANOVA function from the "car" package (Fox and Weisberg 2018). For multiple comparisons and post hoc tests, the estimated marginal means,

TABLE 2. Potato cultivars and breeding clones used in the field trials, their foliar and tuber resistance to Phytophthora infestans (scale from 1 to 9 , with 9 being the most resistant), and maturity groups

\begin{tabular}{|c|c|c|c|}
\hline Cultivar or breeding clone & Foliage resistance: field $^{\mathrm{a}}$ & Tuber resistance: laboratory ${ }^{\mathrm{a}}$ & Maturity $^{\mathrm{b}}$ \\
\hline King Edward & 3 & 5 & Maincrop \\
\hline Rooster ${ }^{c}$ & 3 & 5 & Late \\
\hline Sarpo Mira & 8 & 9 & Very late \\
\hline
\end{tabular}


standard errors, and confidence intervals were calculated with the "emmeans" package (Lenth et al. 2019) and compact letter displays of all pairwise comparisons with the "multcomp" package (Hothorn et al. 2019). The estimates were combined for both models and presented on a point chart with error bars.

Analysis of the microsatellite data. The genotyping data and metadata was collated into a single file and subsequently formatted as GenAlEx comma-separated files to be imported as a genclone object. Frequency charts of genotype proportions per cultivar and fungicide program were created for the two-way contingency tables, to explore possible selection patterns.

Selection patterns between fungicide program, cultivar, and year. The Bruvo distance between MLGs was calculated and minimum spanning networks were constructed to visualize the structure of the population across the studied years in the "Poppr" package (Kamvar et al. 2014). Clustering of genetically similar individuals was sought via discriminant analysis of principal components (DAPC), a multivariate method that uses genetic data to describe the differences between predefined biological populations (Jombart et al. 2010), in the "Adegenet" package (Jombart et al. 2018). In DAPC, data are initially transformed via principal component analysis and subsequently clustered via the $k$-means clustering algorithm. The number of clusters $(K)$ was allowed to vary from 5 to 25 , and the optimal $K$ was determined based on the Bayesian information criterion.

In-season temporal variation of population structure. To provide an overview of how the epidemics progressed in relation to the dynamics of the different $P$. infestans MLGs, the number and the proportion of samples assigned to specific MLGs for each sampling date were calculated for the complete collection, from 2017 to 2019 (Supplementary Table S6). Because MLGs relating to 2016 were collected from a single sampling time point, they were excluded from the analysis. To reduce any potential impact that the more resistant cultivars or fungicide treatments may have had on the $P$. infestans population, a subset of data consisting of samples from plots of susceptible cultivars (King Edward, British Queen, and Rooster), where the epidemics were allowed to develop unimpeded (untreated controls and IRp), were also analyzed. The data are presented via frequency plots.

\section{RESULTS}

Climatic conditions and disease progress. Weather conditions conducive to PLB (Fig. 1), and subsequently, disease progress (Supplementary Fig. S2), varied throughout the years studied. High disease pressure was present in growing seasons 2016, 2017, and 2019 , as evidenced by the high foliar disease levels in plots with susceptible cultivars (King Edward and British Queen) assigned to untreated and IRp programs. The weather was not conducive to PLB in the 2018 growing season, when the highest mean foliar disease level was 25\%. The 2016 and 2017 growing seasons were typical years in terms of PLB development in Ireland. In 2018, PLB development was impeded, because of uncharacteristically high temperatures and a lack of rainfall in June and the first half of July (Fig. 1). A more severe PLB epidemic prevailed in 2019 because of blight-conducive weather conditions experienced throughout the growing season, especially in the latter half of August. The first detections of PLB in the trial site were on 25 July 2016, 3 July 2017, 20 August 2018, and 26 July 2019 (Fig. 1). The onset of epidemics was in accordance with the 25-year average (Dowley et al. 2008), with the exception of the extraordinarily dry 2018, when the first symptoms were observed late in the growing season. In all growing seasons, the epidemics in the untreated control plots for the highly resistant potato cultivars, T5821/11 and Sarpo Mira, started late and developed slowly (Supplementary Fig. S2).

Fungicide applications and dosage reduction. The number of fungicide applications and the proportion of the total label dosage applied varied between DSS-guided fungicide programs, IRp,
BMp, and MIRp (Fig. 2). Over the 4-year period of the experiment, the average number of fungicide applications was 9.3 for the fixed 7-day programs, with eight applications in 2016, 2018, and 2019 and 12 applications in 2017. The number of applications applied in the DSS programs ranged from 1 to 9.3. The IRp received an average of 1 application and $9.7 \%$ of the total dosage applied in the full-dose program. The BMp did not provide any reductions in the number of applications, and the average total dosage ranged from $43.6 \%$ to $87.5 \%$, with a 3-year average of $79.2 \%$. The MIRp received an average of 8.7 fungicide applications because of a single application reduction in 2017 and 2019 and an average total dosage of $41.3 \%$ of the full program applied.

Disease control and impact on the yield. Although the higherorder interactions were present between year, fungicide program, and cultivar, trends were observed in terms of both levels of foliar disease and yield. These are as follows: The IRp performed similarly to the untreated control, with very little difference between other programs (half-dose, MIRp, BMp, and the standard growers' practice) and with the gap between these two groups decreasing and disappearing with higher levels of cultivar resistance or reduced conduciveness of weather conditions in the different years (Fig. 3). Foliar disease levels were highest in the untreated and IRp, and half-dose, MIRp, and BMp were similar to the standard growers' practice for the susceptible and moderately resistant cultivars. The yield levels followed a similar pattern, except in the low-disease year of 2018, which was warm and dry, when there was no difference between the programs. In the other growing seasons, the differences were significant only for the susceptible cultivars. No significant differences in the performance of fungicide programs were identified between the resistant cultivars T5821/11 and Sarpo Mira in terms of either foliar disease levels or yield irrespective of fungicide program or year.

Given the impact of year on disease levels, the results were further examined for each growing season specifically for the susceptible and moderately resistant varieties. In 2016 a single fungicide application was recommended by the IRp at the beginning of the epidemics and provided a significant reduction in foliar disease levels compared with the untreated control on the susceptible 'King Edward' but was insufficient to increase yield over that of the untreated control. The fulldose and half-dose programs provided the best foliar disease control and yield increase on 'King Edward'. Low levels of foliar blight were found on moderately resistant 'Setanta', but only the full-dose program led to an increase in yield. The prolonged epidemic experienced in 2017 led to higher disease levels than in 2016 (Fig. 3). The IRp was not significantly different from the untreated control in terms of either foliar disease control or yield on any cultivar, although two applications were recommended. All other fungicide programs significantly suppressed foliar disease levels and increased yield on the susceptible and moderately resistant cultivars. Because of late disease onset and slow development of the epidemic in 2018, the season finished with low disease levels. The levels of foliar disease observed in the IRp and untreated control plots did not affect yields, which were no different from those of the other fungicide programs. Environmental conditions were favorable for PLB development in 2019 (Fig. 1), resulting in the highest rAUDPC values, compared with all other growing seasons (Fig. 3). Foliar disease levels after the IRp were not significantly different from the untreated control for 'British Queen' and 'King Edward', but it did perform significantly better on 'Rooster' and 'Setanta'. The IRp did not increase yield above that of the unsprayed control for any cultivar. All other fungicide programs suppressed foliar disease and increased yields equivalently on the susceptible and moderately resistant cultivars.

Population structure and selection patterns between fungicide program, cultivar, and year. A total of 1,287 single lesions were successfully genotyped and used to characterize the response of the local population to proposed fungicide programs and potato cultivars during the period 2016 to 2019. The population at Oak Park remained simple, and all samples were associated with 
previously identified MLGs 8A1, 6A1, and 13A2, with the exception of a single sample from 2019, associated with 36A2 MLG (Supplementary Fig. S3). Because of the low frequency of 36A2, this isolate was not included in further analysis.

With the exception of the resistant cultivar Sarpo Mira, collections of 70 to $750 \mathrm{P}$. infestans samples were isolated from the different cultivars over the course of the study (Fig. 4). Low disease levels on 'Sarpo Mira' and difficulties isolating often atypical lesions led to small collections of 25 samples. 13A2 was found at greater frequencies on cultivars with high foliar resistance levels. Conversely, 8A1 was found more frequently on the susceptible cultivars and in similar frequencies, 67.3, 64.9, and 66.2\%, on 'King Edward', 'British Queen', and 'Rooster', respectively.

The corresponding DAPC analysis of the data confirmed the differentiation indicated by the frequency distributions of the MLGs per cultivar. Clear overlaps between clusters of MLG from the

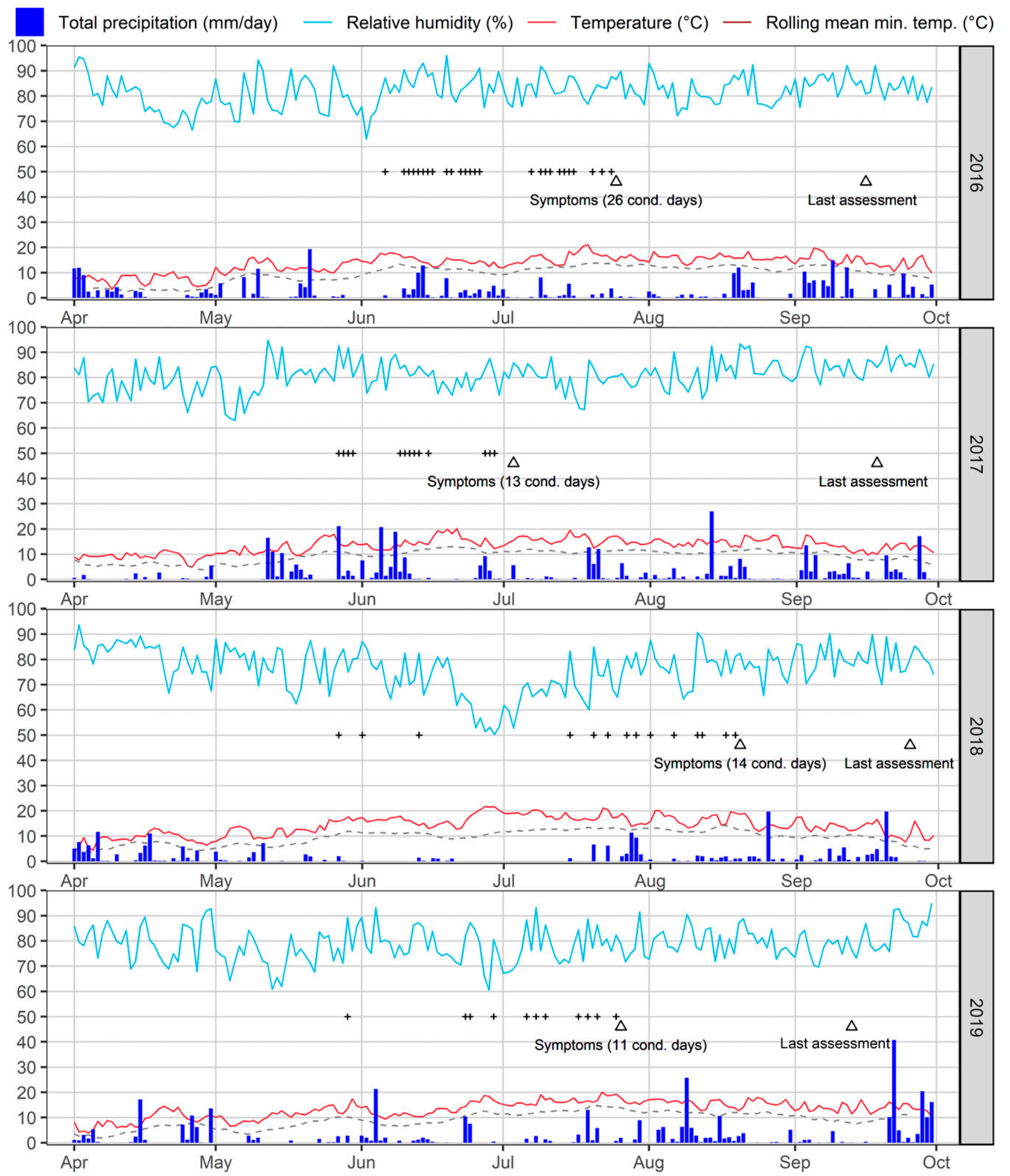

Fig. 1. Daily weather conditions (average temperature and relative humidity, total rain, 10-day rolling mean minimum temperature), disease outbreak and the last assessment periods, and conducive days for the disease outbreak ("+" in the figure), over the course of the study, 2016 through 2019 . Days were considered conducive if a minimum of conditions for blight development were recorded (minimum daily temperature $\geq 10^{\circ} \mathrm{C}$, average daily relative humidity $\geq 80 \%$, and total daily precipitation $\geq 0.2 \mathrm{~mm} /$ day). 
different cultivars were identified, and there was a greater separation between those with moderate to high levels of resistance than those of the susceptible cultivars, which were indistinguishable from one another (Fig. 4). Both the frequency charts and the corresponding DAPC analyses for fungicide treatments suggest limited if any impacts of the different fungicide programs on the population structure. Frequencies of the MLGs varied over the years of the study, with the most obvious difference observed during the dry and warm 2018, when $90.3 \%$ of samples belonged to the $8 \mathrm{~A} 1$ genotype. DAPC indicated slight differences between the structure of annual populations in 2016 to 2018, after which the population from 2019 remained in the same cluster as the one from 2018.

In-season temporal variation of $P$. infestans population structure. There were a total of 13 sampling dates overall: seven in 2017, four in 2018, and two in 2019. An apparent temporal shift of $P$. infestans population was observed in each of the three seasons, with the frequencies of the older MLG 8A1 being reduced in favor of strains belonging to the 6A1 and 13A2 MLG as the epidemics progressed (Fig. 5). In the final sampling in 2017 and 2019, 87.2 and $80 \%$ of all samples and 92.3 and $64 \%$ of the subset collection belonged to 6A1 and 13A2 MLGs, respectively. This shift in pathogen population was less expressed in 2018, when frequencies of $6 \mathrm{~A} 1$ and 13A2 remained low, 11.5 and $17.2 \%$ for full and subset collections, respectively. However, the population structure in 2017 and 2019 was similar to the population structure in 2018, when disease levels were at a comparable level (approximately $25 \%$ in control plots with susceptible cultivars) (Fig. 5).

\section{DISCUSSION}

Potato production is completely reliant on the prophylactic use of fungicides because of the high potential risks of crop loss associated with PLB outbreaks. However, potato producers are faced with increased regulations specifically around reducing these fungicide inputs used to control the disease. These regulations were largely through legislative demands, namely European Community Directive 128/2009 on the Sustainable Use of Pesticides (European Commission 2009), but they are also driven by market demand. The goal of this study was to evaluate whether subtle modifications to standard grower's PLB management practices with environmental risk estimations can lead to reduced usage of chemicals, in terms of both total dosage and number of applications, while providing equal levels of PLB control under Irish conditions. Field performance of the recently modified IR model (Cucak et al. 2019), the currently used IR model (Austin Bourke 1953), and the limited version of Blight Management (Nielsen et al. 2018) was evaluated on cultivars with different levels of PLB resistance, and the response in the structure of $P$. infestans population was monitored.

Although all three forecasting schemes provided a significant reduction in fungicide usage compared with the full-label standard grower's program, only the BMp and the MIRp did so without sacrificing disease control. Overall, the two best-performing programs were MIRp and half-dose, with MIRp requiring slightly lower inputs than the halfdose program. Most importantly for Irish potato cultivation, the IRp was demonstrated to provide unacceptable levels of disease control on cultivars with low and medium levels of blight resistance. Such cultivars constitute the majority of the Irish potato production. However, levels of foliar disease control achieved by both the BMp and the MIRp were not different from those of the half-dose or full-dose fungicide programs. The higher mean fungicide usage required by the BMp of $79.2 \%$, compared with the other DSS-based programs, may in part be caused by a limited implementation of the Blight Management DSS. The limitations were as follows: Only model A (for susceptible cultivars) was used because of our experimental design constraints, later planting dates caused dosage correction to be based mostly on the high infection pressure tiers of the model dosage correction, and the predefined fungicide program was not altered to accommodate the curative treatments recommended by the system.

No differences in disease control or yield were achieved across fungicide programs among the resistant cultivars included in our
Programme: 1.Untreated Control
2.Full dose $(100)$
3. Half dose (50) 4.Irish Rules (IRp)
5.Blight Man. (BMp)

6.Modified I. R. (MIRp)
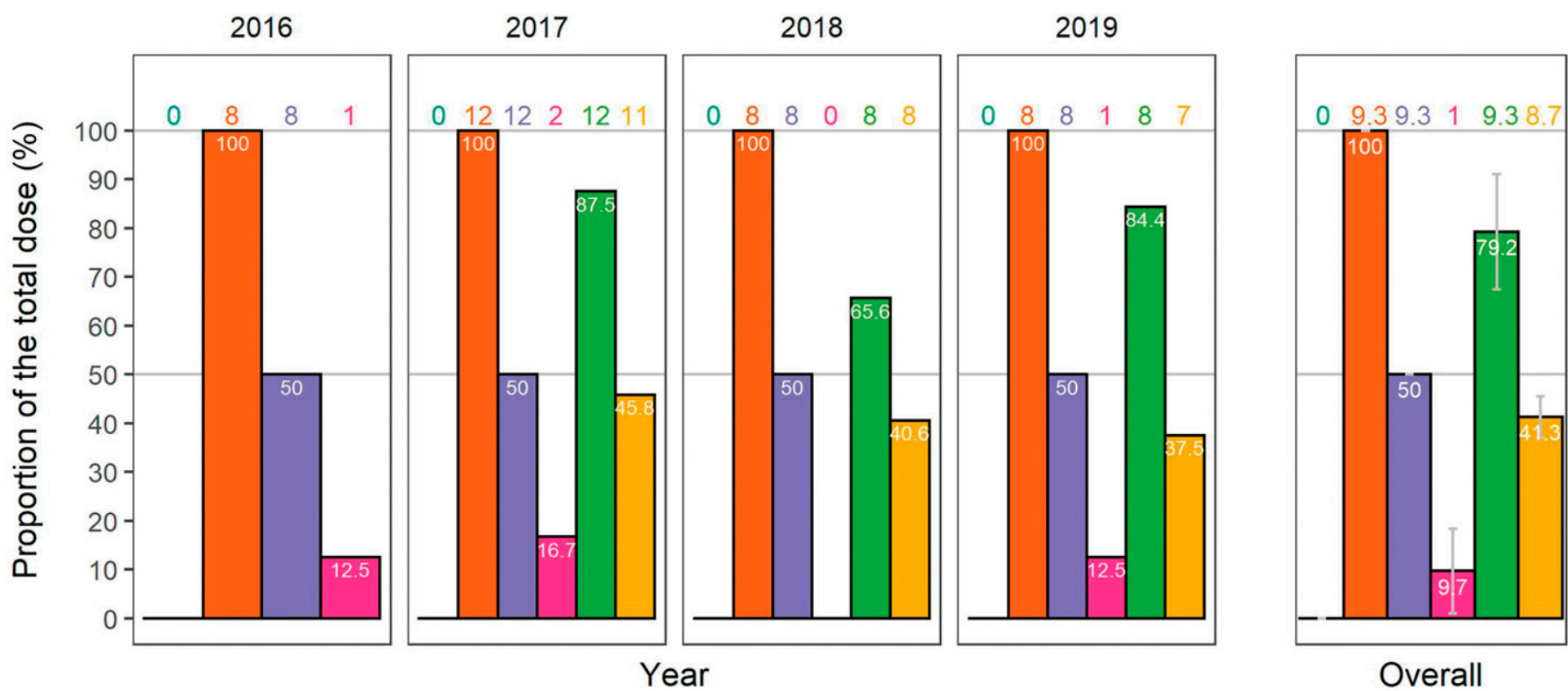

Fig. 2. Proportion of the total label dosage and the number of fungicide applications per year by the fixed and varying dose programs. Graphs marked with

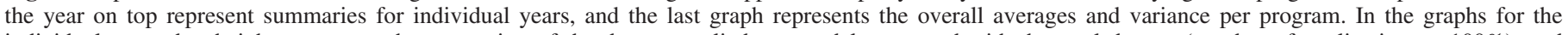

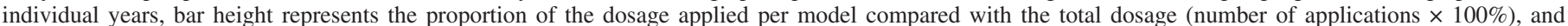

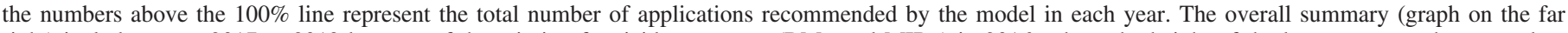

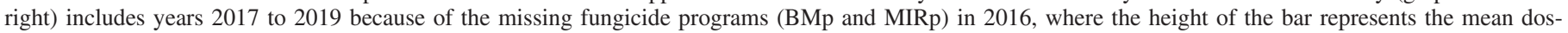
age reduction, the error bars represent the standard deviation, and the number above the bar is the mean number of applications during the year. 
trials, demonstrating the value of cultivar resistance in controlling PLB. Disease levels remained low across the growing seasons on the two most resistant cultivars, 'T5821/11' and 'Sarpo Mira', with epidemic onset only late in the season. These epidemics were probably initiated because of maturity-induced reduction of polygenetic resistance (Fry and Apple 1986), high disease pressure, and inflow of the strains belonging to more aggressive MLGs. All three forecasting schemes indicated such periods of high disease pressure in August 2019 and recommended a full-dose fungicide application, reducing chances of the disease outbreak on resistant cultivars and depletion of cultivar resistance. Although the half-dose program provided similar disease control to the full-dose and DSS adjusted-dose
A
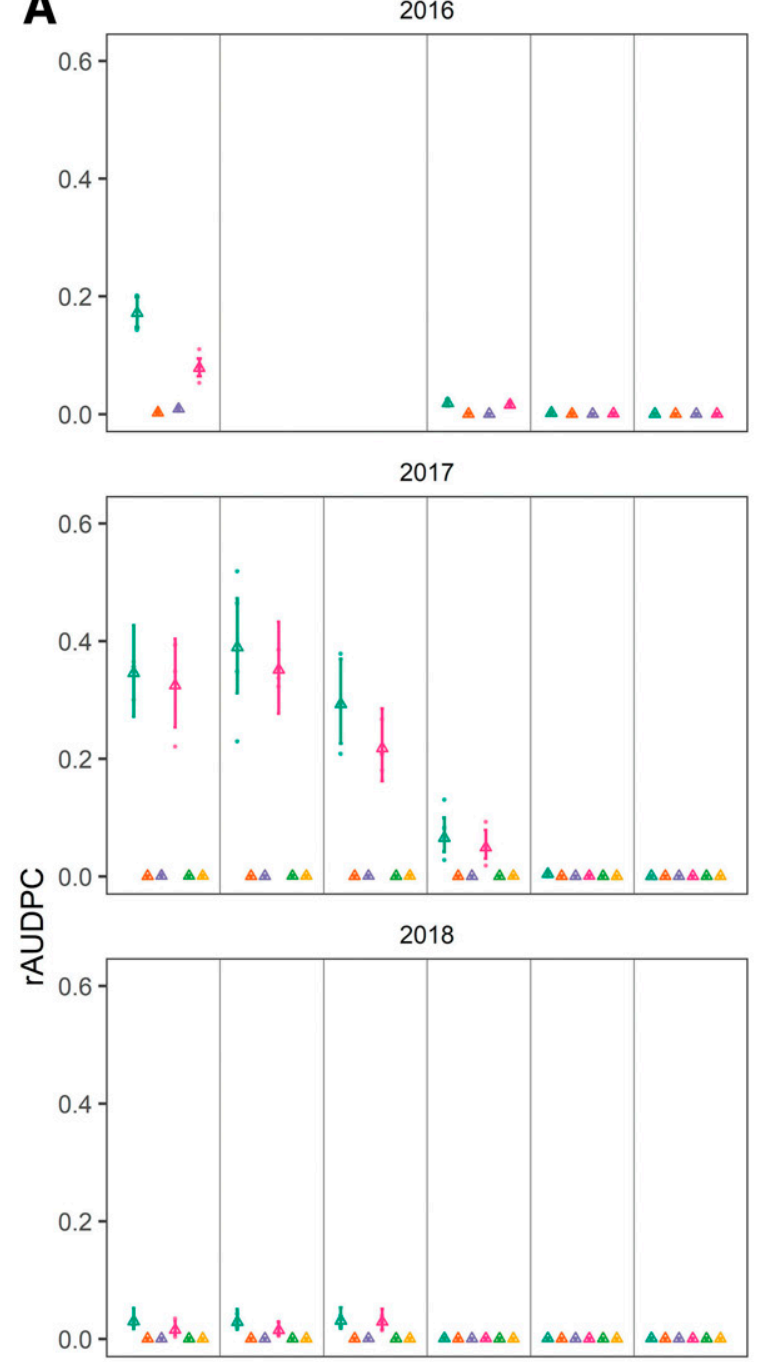

2019

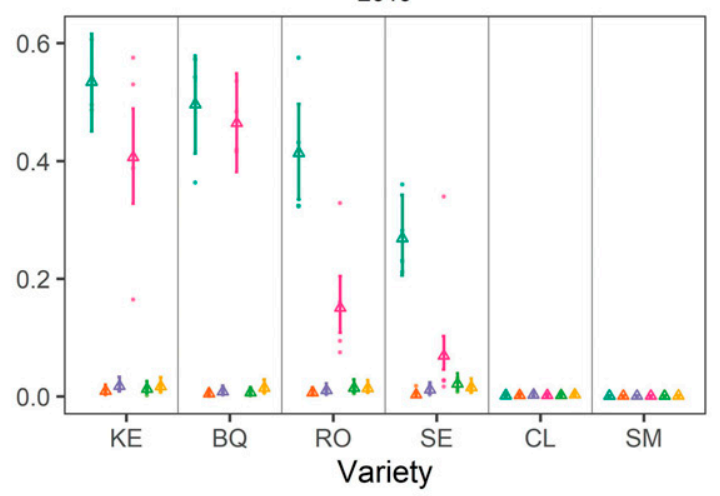

B
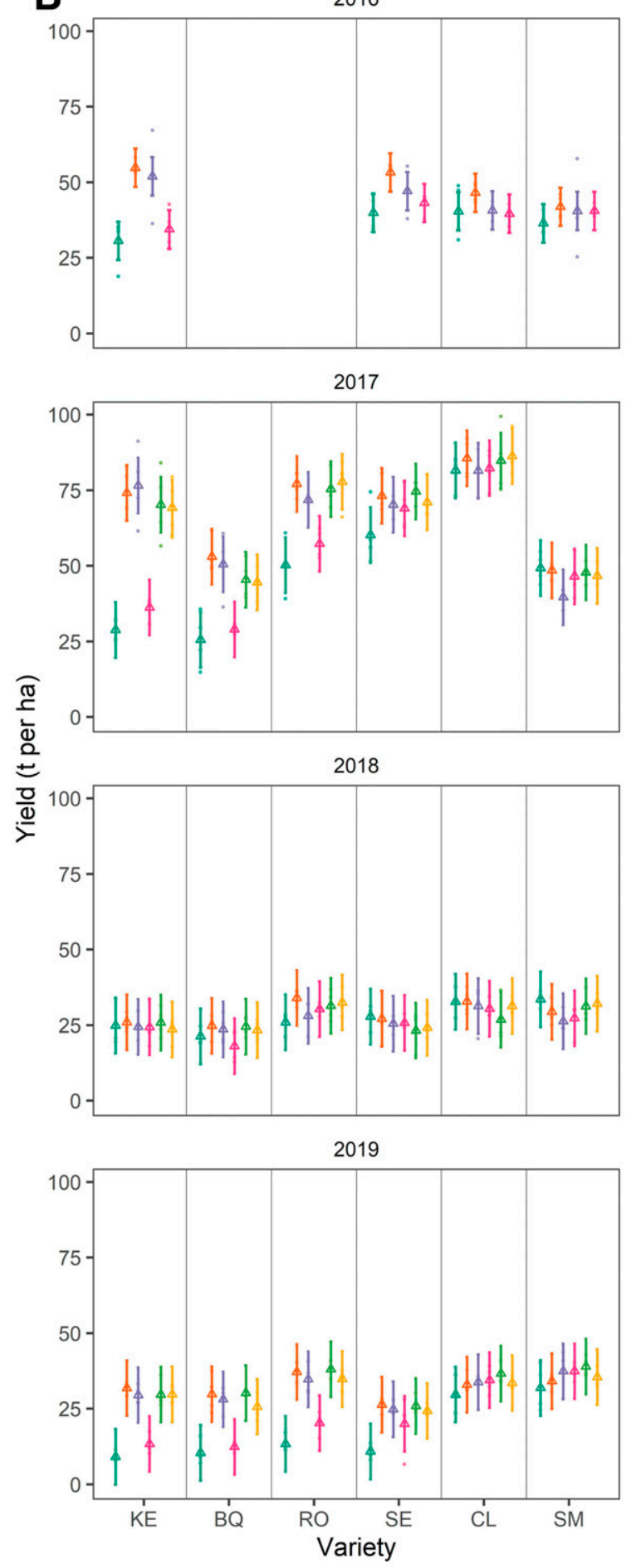

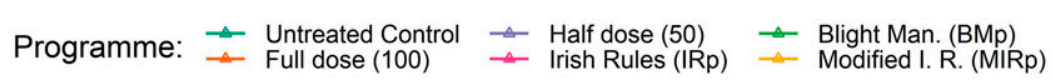

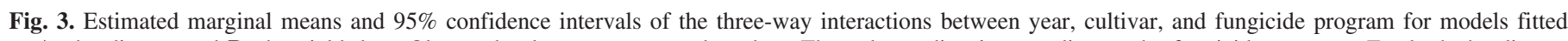

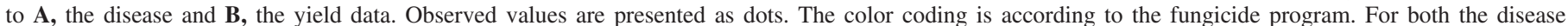

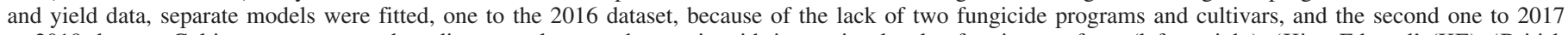

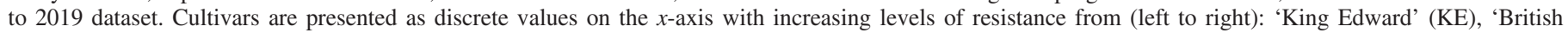
Queen' (BQ), 'Rooster' (RO), 'Setanta' (SE), the clone from Teagasc breeding program T5821/11 (CL), and 'Sarpo Mira' (SM). 
programs, with the exception of IRp, we advise that the fungicide dosage should be adjusted according to the estimated disease risk for two reasons. First, although the MIRp had only slightly lower application frequencies and doses applied when compared with the halfrate program, it is feasible that in extremely dry seasons further reductions can be achieved in the confidence that it will not adversely increase the risk of the loss of control. Second, as Carolan et al. (2017) demonstrated, the use of fungicides for late blight control is a key tool in reducing the rate of epidemic growth and ultimately protection of cultivar resistance from the highly adaptive potential of $P$.

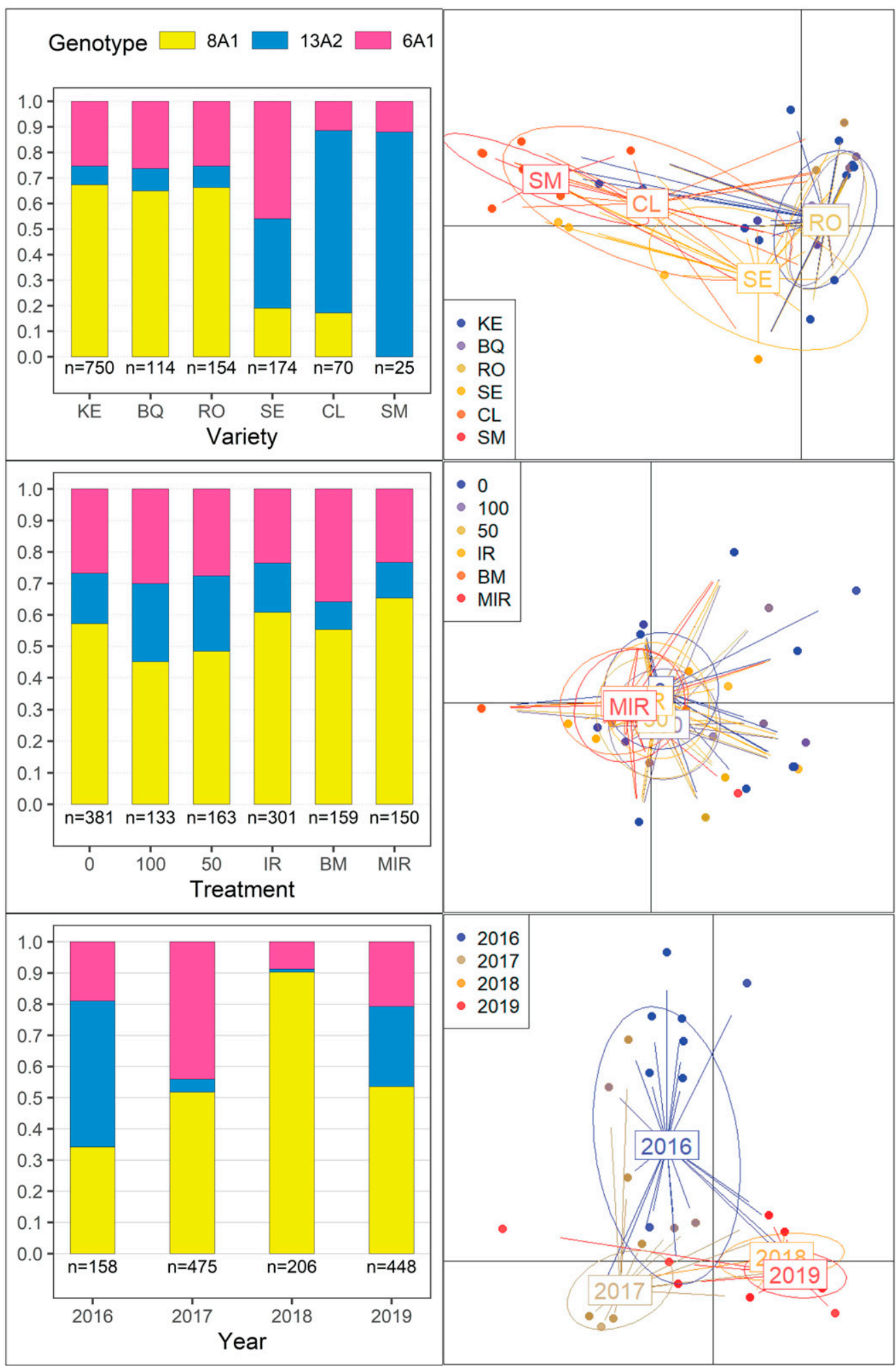

Fig. 4. Relative frequencies (bar charts on the left) and discriminant analysis of principal components (DAPC) (right) of Phytophthora infestans populations sampled at the field trial at Oak Park, 2016 to 2019. Samples were pooled per cultivar (top row), fungicide program (middle row), and year (bottom row), disregarding the sampling date. Cultivars are presented as discrete values on the $x$-axis with increasing levels of resistance from (left to right) (upper left chart) and labels (upper right DAPC scatterplot): 'King Edward' (KE), 'British Queen' (BQ), 'Rooster' (RO), 'Setanta' (SE), the clone from Teagasc breeding program T5821/11 (CL), and 'Sarpo Mira' (SM). Programs are presented as discrete values on the $x$-axis: Untreated control (0), half dose (50), full dose (100), Irish Rules (IR), Blight Management (BM), and Modified Irish Rules (MIR). 
infestans. However, fungicides themselves are equally at risk from resistance development in $P$. infestans populations, and to delay the selection for fungicide resistance, they should be used only when necessary and at dosages reflective of the protection needed (van den Bosch et al. 2011). The flexibility in dosage and application frequency provided through accurate forecasting ensures that the rate of epidemic growth is kept to a minimum, but equally the dosages applied reflect the protection needed. This was evident in the presented trials, with the overall total dosage and frequency of fungicides applied in the MIRp $(41.3 \%$ of full dose and a mean application frequency of 8.7) slightly lower than those of the halfdose program (50\% of full dose and mean application frequency of 9.3), but with instances where the full dosage was needed in specific applications because risk was deemed extremely high.

Our results related to the $P$. infestans population structure are in agreement with previous reports from the Republic of Ireland (Kildea et al. 2010; Stellingwerf et al. 2018). SSR analysis of samples collected in our trials indicated that the genetic composition of the $P$. infestans population at Oak Park, and probably its immediate surroundings, remains simple, with only three major MLGs (13A2, 6A1, and 8A1) dominating in all years. Curiously, although the older MLG 8A1 has been displaced by strains with higher levels of aggressiveness throughout northwestern Europe (e.g., 13A2, 6A1 [Cooke et al. 2012; Mariette et al. 2016] and more recently 36A2, EU_37_A2, and EU_41_A2 [Cooke et al. 2019]), 8A1 was detected at high frequencies in our field trials. Although the most dominant European MLGs of $P$. infestans do arrive in Ireland, their emergence and establishment seem to be delayed. A possible reason for such delay could be the geographic barrier that restricts the inflow of viable inoculum from Great Britain or continental Europe.
For example, the arrival of 36A2 MLG in Ireland was first confirmed in our study, with a single sample identified in the 2019 collection, although it was present in Europe from 2014 (Cooke et al. 2019).

The observed selection patterns on local $P$. infestans populations related to cultivars with higher PLB resistance levels are in agreement with those from Stellingwerf et al. (2018), indicating that more resistant cultivars are selecting newer genotypes, 13A2 and 6A1. This is especially pronounced in the case of highly resistant cultivar Sarpo Mira, which contains multiple $\mathrm{R}$ genes and one quantitative trait locus (Rietman et al. 2012). Although Irish potato production is reliant on susceptible cultivars, hobby and organic growers rely mostly on resistant cultivars, with 'Sarpo Mira' being one of the popular choices. Because of the low fungicide input approach among these groups, disease levels are often high, potentially leading to selection of more virulent strains and increase in their frequency in local populations (Fry 2008). Therefore, the previously described periods of high risk indicated by models should be used to guide the limited fungicide protection by these groups. However, Stellingwerf et al. (2018) did report selection patterns between the susceptible cultivars Desiree and King Edward. However, contrary to their findings, we did not observe any such pattern between the three susceptible cultivars included in our trials: 'King Edward', 'British Queen', and Rooster, of which the last two constitute more than two thirds of the conventional Irish potato production (Anonymous 2011). No selection pattern was observed between the samples collected across the different fungicide programs. Stellingwerf et al. (2018) also found no impacts of fungicide treatment on local $P$. infestans composed of similar MLGs, although their programs were fungicide specific, unlike those included in present study.

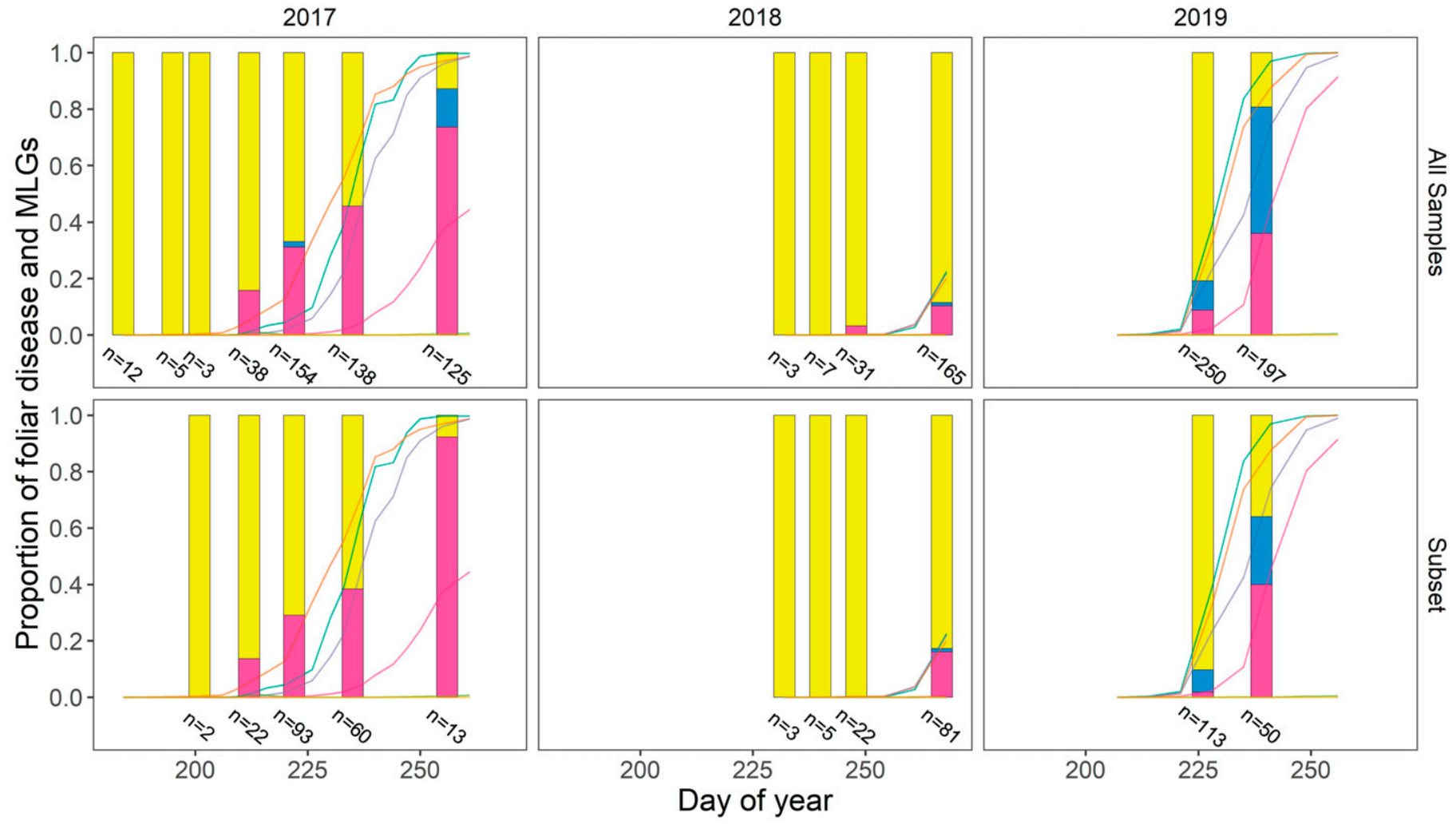

Variety:

$-\mathrm{KE}-\mathrm{BQ}-\mathrm{RO}-\mathrm{SE}-\mathrm{CL}-\mathrm{SM} \square 8 \mathrm{~A} 1$

MLG:

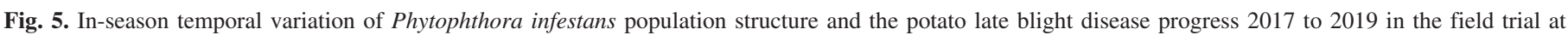

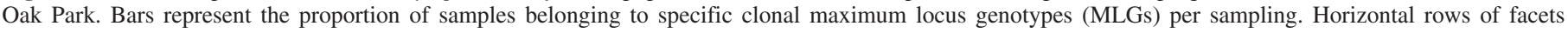

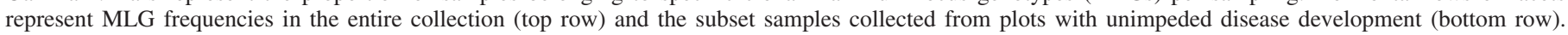

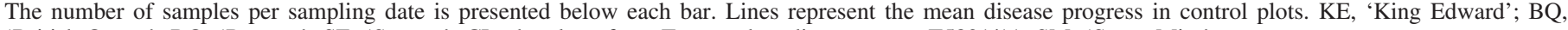
'British Queen'; RO, 'Rooster'; SE, 'Setanta'; CL, the clone from Teagasc breeding program T5821/11; SM, 'Sarpo Mira'. 
The natural infections and sequential sampling in our trials allowed us to gain some insight into $P$. infestans seasonal population dynamics under Irish conditions. Although the epidemics were initiated by the 8A1 MLG, frequencies of strains belonging to $6 \mathrm{~A} 1$ and 13A2 MLGs increased during the potato growing season, with the rate of change depending on the rate of disease progression or cultivar resistance. However, these results should be interpreted with caution because of limitations in terms of the number of samples and sampling dates during the three growing seasons. Such findings may be explained by trade-offs between pathogenicity (within-season fitness) and survival (between-season fitness) shaping the invasive potential of lineages (Andrivon et al. 2013). Higher aggressiveness (e.g., short latency period, high spore production, high lesion growth rate) could provide a comparative advantage during epidemics (Montarry et al. 2007) but may reduce asexual transmission between seasons (Andrivon et al. 2007). Additional studies in controlled environments investigating phenotypic traits between the different MGLs identified in current study are needed to verify the trends observed in the populations in these trials. Although current DSSs, including MIR, are optimized to a simple generic model of $P$. infestans biology (Leesutthiphonchai et al. 2018), further understanding of $P$. infestans interseason and intraseason population dynamics and assessment of phenotypic traits of dominant MLGs could lead to increases in their complexity, accuracy, and reliability. However, such improvements would necessitate an increase in the model complexity, which could cause challenges in operational application, such as reliance on forecasted weather data. However, our results indicate that the outputs of models based on weather forecast with high spatiotemporal resolution can produce a reliable risk prediction for $\leq 7$ days. This limitation could be explained by the simplicity of the models used in our study, which do not require precise predictions beyond the developmental thresholds set within the models used, but it illustrates the need to develop and test the more complex models.

Decision support tools in crop protection are merely the reflection of current knowledge of the pathosystem. Models of natural systems are fluid, like the systems they are interpreting, and in need of constant validation and revision to capture the changes in these systems, whether they are related to the host, pathogen, environment, or agronomic practices. For example, the occurrence of the new $P$. infestans MLGs in Ireland might affect the accuracy of the MIR model in the future; consequently, there is a need for constant evaluation of models used. Many DSSs have not stood the test of time because of a lack of sustainable solutions to extend their lifespan beyond the duration of the project they were developed in (Shtienberg 2013). To enable validation and possible recalibration of the model in the Republic of Ireland and elsewhere, this analysis and the model recalibration based on historical data (Cucak et al. 2019) presented here are highly reproducible, implemented via a single open-access computing platform, the R language. Such resources are lacking in the field of plant pathology (Kamoun et al. 2019) and are important for a new plant pathologist entering the field, as well as for the experienced ones.

\section{ACKNOWLEDGMENTS}

We thank the Teagasc potato breeding team, especially Colum Kennedy and Denis Griffin, for their help and resources; Sinead Phelan, Fiona Hutton, Helena Mealy, and Jeroen Stellingwerf and for the help and guidance in the laboratory; and Emily Connaghan from the Department of Agriculture, Food and the Marine (DAFM) for the use of the fragment analyzer. We also thank Jens Grønbech Hansen for sharing the code and the instructions for Blight Management, the Danish potato late blight forecasting system.

\section{LITERATURE CITED}

Andrivon, D., Montarry, J., Corbière, R., Pasco, C., Glais, I., Marquer, B., Clément, J. A. J., Castel, M., and Hamelin, F. M. 2013. The hard life of
Phytophthora infestans: When trade-offs shape evolution in a biotrophic plant pathogen. Plant Pathol. 62:28-35.

Andrivon, D., Pilet, F., Montarry, J., Hafidi, M., Corbière, R., Achbani, E. H., Pellé, R., and Ellissèche, D. 2007. Adaptation of Phytophthora infestans to partial resistance in potato: Evidence from French and Moroccan populations. Phytopathology 97:338-343.

Anonymous. 1976. Manual of plant growth stage and disease assessment keys. Plant Pathol. 25:205-207.

Anonymous. 2011. Trends \& challenges in Irish potato production. The Irish Farmers' Association.

Austin Bourke, P. M. 1953. Potato blight and the weather: A fresh approach. Irish Meteorological Service.

Austin Bourke, P. M. 1955. The forecasting from weather data of potato blight and other plant diseases and pests. WMO technical note no. 11. WMO, Geneva, Switzerland.

Austin Bourke, P. M. 1959. Meteorology and the timing of fungicide applications against potato blight. Int. J. Biometeorol. 3:71-78.

Austin Bourke, P. M. 1964. Emergence of potato blight, 1843-46. Nature 203:805-808.

Bain, R. A., Ritchie, F., Lees, A., and Dyer, C. 2014. Impact of fungicide input on leaf blight (Phytophthora infestans) development on different potato cultivars. Pages 65-73 in: Proceedings of the Fourteenth EuroBlight Workshop, Limassol, Cyprus.

Bates, D., Maechler, M., Bolker, B., Walker, S., Christensen, R. H. B., Singmann, H., Dai, B., Grothendieck, G., Green, P., and Bolker, M. B. 2015. Package 'Ime4'. Convergence 12:470-474.

Brooks, M. E., Kristensen, K., van Benthem, K. J., Magnusson, A., Berg, C. W., Nielsen, A., Skaug, H. J., Mächler, M., and Bolker, B. M. 2017. glmmTMB balances speed and flexibility among packages for zero-inflated generalized linear mixed modeling. R J. 9:378-400.

Campbell, C. L., and Madden, L. V. 1990. Introduction to Plant Disease Epidemiology. John Wiley \& Sons, New York, NY.

Carolan, K., Helps, J., van den Berg, F., Bain, R., Paveley, N., and van den Bosch, F. 2017. Extending the durability of cultivar resistance by limiting epidemic growth rates. Proc. R. Soc. B Biol. Sci. 284:20170828-36.

Caten, C. E., and Jinks, J. L. 1968. Spontaneous variability of single isolates of Phytophthora infestans. Can. J. Bot. 46:329-348.

Cooke, D. E., Cano, L. M., Raffaele, S., Bain, R. A., Cooke, L. R., Etherington, G. J., Deahl, K. L., Farrer, R. A., Gilroy, E. M., Goss, E. M., Grünwald, N. J., Hein, I., MacLean, D., McNicol, J. W., Randall, E., Oliva, R. F., Pel, M. A., Shaw, D. S., Squires, J. N., Taylor, M. C., Vleeshouwers, V. G. A. A., Birch, P. R. J., Lees, A. K., and Kamoun, S. 2012. Genome analyses of an aggressive and invasive lineage of the Irish potato famine pathogen. PLoS Pathog 8:e1002940.

Cooke, D. E. L., Kessel, G. J. T., Lassen, P., and Hansen, J. G. 2019. The European population of Phytophthora infestans in a global context. WUR special report no. 19:35-36.

Cooke, L. R., Quinn, L., Nugent, P., Walker, E., and Schepers, H. 2014. The potato blight population in Northern Ireland in 2012: ongoing changes and fungicide performance. In PPO special report 16:145-152.

Cooke, L. R., Schepers, H. T. M., Hermansen, A., Bain, R. A., Bradshaw, N. J., Ritchie, F., et al. 2011. Epidemiology and integrated control of potato late blight in Europe. Potato Res. 54:183-222.

Copeland, R., Dowley, L., and Moore, J. 1993. Vulnerability of the Irish potato industry to harmful organisms. Pages 95-106 in: Proceedings of Royal Irish Academy Seminar.

Cucak, M., Sparks, A., Moral, R. de A., Kildea, S., Lambkin, K., and Fealy, R. 2019. Evaluation of the "Irish Rules": The potato late blight forecasting model and its operational use in the Republic of Ireland. Agronomy (Basel) 9:515.

Dowley, L. J., and Burke, J. J. 2004. Field validation of four decision support systems for the control of late blight of potatoes in Ireland. Potato Res. 47:151-162.

Dowley, L. J., Grant, J., and Griffin, D. 2008. Yield losses caused by late blight (Phytophthora infestans (Mont.) de Bary) in potato crops in Ireland. Ir. J. Agric. Food Res. 47:69-78.

Environmental Protection Agency. 2014. Irish soil information system.

European Commission. 2009. Development of Guidance for Establishing Integrated Pest Management (IPM) Principles. Final report 07.0307/2008/ 504015/ETU/B3. BiPRO (Beratungsgesellschaft für integrierte Problemlösungen), Munich, Germany.

Forsythe, G. E., Malcolm, M. A., and Moler, C. B. 1977. Computer Methods for Mathematical Computations. Prentice-Hall, Englewood Cliffs, NJ.

Fox, J., and Weisberg, S. 2018. An R Companion to Applied Regression. SAGE Publications, Thousand Oaks, CA.

Fry, W. 2008. Phytophthora infestans: The plant (and R gene) destroyer. Mol. Plant Pathol. 9:385-402.

Fry, W. E. 1975. Integrated effects of polygenic resistance and a protective fungicide on development of potato late blight. Phytopathology 65:908. 
Fry, W. E. 1978. Quantification of general resistance of potato cultivars and fungicide effects for integrated control of potato late blight. Phytopathology 68:1650-1655.

Fry, W. E. 2016. Phytophthora infestans: New tools (and old ones) lead to new understanding and precision management. Annu. Rev. Phytopathol. 54:529-547.

Fry, W. E., and Apple, A. E. 1986. Disease management implications of age-related changes in susceptibility of potato foliage to Phytophthora infestans. Am. Potato J. 63:47-56.

Fry, W. E., Apple, A. E., and Bruhn, J. A. 1983. Evaluation of potato late blight forecasts modified to incorporate host resistance and fungicide weathering. Phytopathology 73:1054-1059.

Gent, D. H., De Wolf, E., and Pethybridge, S. J. 2010. Perceptions of risk, risk aversion, and barriers to adoption of decision support systems and integrated pest management: An introduction. Phytopathology 101:640-643.

Goodwin, S. B., Cohen, B. A., and Fry, W. E. 1994. Panglobal distribution of a single clonal lineage of the Irish potato famine fungus. Proc. Natl. Acad. Sci. USA 91:11591-11595.

Goodwin, S. B., and Drenth, A. 1997. Origin of the A2 mating type of Phytophthora infestans outside Mexico. Phytopathology 87:992-999.

Grünwald, N. J., Montes, G. R., Saldaña, H. L., Covarrubias, O. A. R., and Fry, W. E. 2002. Potato late blight management in the Toluca Valley: Field validation of SimCast modified for cultivars with high field resistance. Plant Dis. 86:1163-1168.

Hansen, J. G., Lassen, P., Hjelkrem, A.-G. R., Eikemo, H., Cucak, M., Lees, A., et al. 2017. Integration of pathogen and host resistance information in existing DSSs: Introducing the IPMBlight2. 0 approach. PPO. Spec. Rep. 18:147-158.

Harrison, J. G. 1995. Factors involved in the development of potato late blight disease (Phytophthora infestans). Pages 215-236 in: Potato Ecology and Modelling of Crops Under Conditions Limiting Growth: Proceedings of the Second International Potato Modeling Conference, Wageningen, Current Issues in Production Ecology, A. J. Haverkort and D. K. L. MacKerron, eds. Springer, Dordrecht, the Netherlands

Haverkort, A. J., Boonekamp, P. M., Hutten, R., Jacobsen, E., Lotz, L. A. P., Kessel, G. J. T., Visser, R. G. F., and Van der Vossen, E. A. G. 2008. Societal costs of late blight in potato and prospects of durable resistance through cisgenic modification. Potato Res. 51:47-57.

Hermansen, A., and Amundsen, T. 2003. Evaluation of old potato late blight forecasting rules during 1994-1999 in fields with the new Phytophthora infestans population in Norway. Acta Agric. Scand. B Soil Plant Sci. 53: $118-128$

Hothorn, T., Bretz, F., Westfall, P., Heiberger, R. M., Schuetzenmeister, A., and Scheibe, S. 2019. multcomp: Simultaneous inference in general parametric models. https://CRAN.R-project.org/package=multcomp

Jombart, T., Devillard, S., and Balloux, F. 2010. Discriminant analysis of principal components: A new method for the analysis of genetically structured populations. BMC Genet. 11:94.

Jombart, T., Kamvar, Z. N., Collins, C., Lustrik, R., Beugin, M.-P., Knaus, B. J., Solymos, P., Mikryukov, V., Schliep, K., Maié, T., Morkovsky, L., Ahmed, I., Cori, A., Calboli, F., Ewing, R. J., Michaud, F., DeCamp, R., and Courtiol, A. 2018. adegenet: Exploratory analysis of genetic and genomic data. https:// CRAN.R-project.org/package=adegenet

Kamoun, S., Talbot, N. J., and Islam, M. T. 2019. Plant health emergencies demand open science: Tackling a cereal killer on the run. PLoS Biol. 17: e3000302.

Kamvar, Z. N., Tabima, J. F., and Grünwald, N. J. 2014. Poppr: An R package for genetic analysis of populations with clonal, partially clonal, and/or sexual reproduction. PeerJ 2:e281.

Kessel, G. J. T., Mullins, E., Evenhuis, A., Stellingwerf, J., Cortes, V. O., Phelan, S., et al. 2018. Development and validation of IPM strategies for the cultivation of cisgenically modified late blight resistant potato. Eur. J. Agron. 96:146-155.

Kildea, S., Cooke, L., Quinn, L., Little, G., Armstrong, C., Hutton, F., Dowley, L. J., and Griffin, D. 2010. Changes within the Irish potato late blight population. PPO Special Report 14:147-150.

Kirk, W. W., Felcher, K. J., Douches, D. S., Coombs, J., Stein, J. M., Baker, K. M., et al. 2001. Effect of host plant resistance and reduced rates and frequencies of fungicide application to control potato late blight. Plant Dis. 85:1113-1118.

Knapova, G., Schlenzig, A., and Gisi, U. 2002. Crosses between isolates of Phytophthora infestans from potato and tomato and characterisation of F1 and F2 progeny for phenotypic and molecular markers. Plant Pathol. 51: 698-709.

Lees, A. K., Stewart, J. A., Lynott, J. S., Carnegie, S. F., Campbell, H., and Roberts, A. M. I. 2012. The effect of a dominant Phytophthora infestans genotype (13_A2) in Great Britain on host resistance to foliar late blight in commercial potato cultivars. Potato Res. 55:125-134.

Lees, A. K., Wattier, R., Shaw, D. S., Sullivan, L., Williams, N. A., and Cooke, D. E. L. 2006. Novel microsatellite markers for the analysis of Phytophthora infestans populations. Plant Pathol. 55:311-319.

Leesutthiphonchai, W., Vu, A. L., Ah-Fong, A. M. V., and Judelson, H. S. 2018. How does Phytophthora infestans evade control efforts? Modern insight into the late blight disease. Phytopathology 108:916-924.

Li, Y., Cooke, D. E. L., Jacobsen, E., and van der Lee, T. 2013. Efficient multiplex simple sequence repeat genotyping of the oomycete plant pathogen Phytophthora infestans. J. Microbiol. Methods 92:316-322.

Li, Y., Govers, F., Mendes, O., Testa, A., Jacobsen, E., Huang, S., et al. 2010. A new set of highly informative SSR markers for Phytophthora infestans population analysis assembled into an efficient multiplex. Mol. Ecol. Resour. 10:1098-1105.

Madden, L. V., and Ellis, M. A. 1988. How to develop plant disease forecasters. Pages 191-208 in: Experimental Techniques in Plant Disease Epidemiology. J. Kranz and J. Rotem, eds. Springer, Berlin.

Madden, L. V., Turechek, W. W., and Nita, M. 2002. Evaluation of generalised linear mixed models for analyzing disease incidence data obtained in designed experiments. Plant Dis. 86:316-325.

Malcolmson, J. F. 1969. Factors involved in resistance to blight (Phytophthora infestans (Mont.) de Bary) in potatoes and assessment of resistance using detached leaves. Ann. Appl. Biol. 64:461-468.

Mariette, N., Mabon, R., Corbière, R., Boulard, F., Glais, I., Marquer, B., Pasco, C., Montarry, J., and Andrivon, D. 2016. Phenotypic and genotypic changes in French populations of Phytophthora infestans: Are invasive clones the most aggressive? Plant Pathol. 65:577-586.

Mendiburu, F. 2014. Agricolae: statistical procedures for agricultural research. R package version. 1. http://tarwi.lamolina.edu.pe/ fmendiburu

Montarry, J., Corbiere, R., and Andrivon, D. 2007. Is there a trade-off between aggressiveness and overwinter survival in Phytophthora infestans? Funct. Ecol. 21:603-610.

Moral, R. A., Hinde, J., and Demétrio, C. G. 2017. Half-normal plots and overdispersed models in R: The hnp package. J. Stat. Softw. 81:1-23.

Nærstad, R., Hermansen, A., and Bjor, T. 2007. Exploiting host resistance to reduce the use of fungicides to control potato late blight. Plant Pathol. 56: $156-166$

Nielsen, B. J., Abuley, I. K., and Hansen, H. 2018. Control of late blight (Phytophthora infestans) and early blight (Alternaria solani \& A. alternata) in potatoes. Appl. Crop Prot. 8:69-120.

Pethybridge, S. J., Gent, D. H., Esker, P. D., Turechek, W. W., Hay, F. S., and Nutter, F. W. 2009. Site-specific risk factors for ray blight in Tasmanian pyrethrum fields. Plant Dis. 93:229-237.

R Core Team. 2018. R: A language and environment for statistical computing. R Foundation for Statistical Computing, Vienna, Austria. https:// www.R-project.org/

Raatjes, P., Hadders, J., Martin, D., and Hinds, H. 2004. PLANT-Plus: turnkey solution for disease forecasting and irrigation management. Pages 169-185 in: Decision Support Systems in Potato Production: Bringing Models Into Practice. Wageningen Academic Publishers, Wageningen, the Netherlands

Rietman, H., Bijsterbosch, G., Cano, L. M., Lee, H.-R., Vossen, J. H., Jacobsen, E., et al. 2012. Qualitative and quantitative late blight resistance in the potato cultivar Sarpo Mira is determined by the perception of five distinct RXLR effectors. Mol. Plant-Microbe Interact. 25:910-919.

Savary, S., Bregaglio, S., Willocquet, L., Gustafson, D., D’Croz, D. M., Sparks, A., et al. 2017. Crop health and its global impacts on the components of food security. Food Secur. 9:311-327.

Shtienberg, D. 2013. Will decision-support systems be widely used for the management of plant diseases? Annu. Rev. Phytopathol. 51:1-16.

Small, I. M., Joseph, L., and Fry, W. E. 2015. Evaluation of the BlightPro decision support system for management of potato late blight using computer simulation and field validation. Phytopathology 105:1545-1554.

Spits, H., Evenhuis, A., and Schepers, H. 2007. Fungicide dose rates \& cultivar resistance, results of five years of field experiments in the Netherlands. Pages 165-170 in: Proceedings of the Tenth Workshop of an European Network for Development of an Integrated Control Strategy of Potato Late Blight.

Stellingwerf, J. S., Phelan, S., Doohan, F. M., Griffin, D., Bourke, A., Hutten, R. C. B., et al. 2018. Evidence for selection pressure from resistant potato genotypes but not from fungicide application within a clonal Phytophthora infestans population. Plant Pathol. 67:1528-1538.

van den Bosch, F., Paveley, N., Shaw, M., Hobbelen, P., and Oliver, R. 2011. The dose rate debate: Does the risk of fungicide resistance increase or decrease with dose? Plant Pathol. 60:597-606. 